\title{
Recent Trends and Technologies in Legal Training
}

\author{
Nikolay NikolaevichGorach,Tatiana VyacheslavnaMaltseva, Aleksandr Semchenko,Ekaterina \\ Anatol'evnaSumina, Sergey AlexandrovichKhmelev,Ekaterina AlekseevnaTrishkina,Svetlana \\ Belova
}

\begin{abstract}
This article elaborates the concept and the essence of the problem-communicative approach as applied to law training. The conducted research has helped devise and justify the methodological rules for its application. Also, the article describes the results of the problem-communicative approach implementation.
\end{abstract}

Keywords: the problem-communicative approach, results-based education, university.

\section{INTRODUCTION}

Nowadays, the higher education faces severe problems the majority of which are unlikely to be solved in the nearest future due to their complexity. This inhibits the sustainable development of Russia and prevents the country from entering the global educational community. The further development of the national education system is urgent and should adhere to the principle of continuity: the reforms are evolutionary in nature, experience and achievements of the previous system are taken into account. On the other hand, it is important to develop new conceptual approaches based on the analytical assessments and strategical directions of the country's economy and social policy.

The main ideas should be:

- Updating the content of education and developing new educational technologies;

- Creating new programs, professions, and specializations;

- Developing multidisciplinary and transdisciplinary, problem-oriented research aimed at elaborating new technologies in the key areas of the economy to avoid studying them in separate fields of science;

- Further developing of culture and spirituality through “ the interconnection between the cognition and sociocultural context" [1].

Revised Manuscript Received on November 15, 2019

Nikolay NikolaevichGorach, Moscow Academy of the Investigative Committee of the Russian Federation, Moscow University of the Ministry of Internal Affairs of Russia named by V.Ya. Kikot, Moscow, Russia.

Tatiana VyacheslavnaMaltseva, Academy of management of the Ministry of Internal Affairs of Russia, Moscow, Russia

Aleksandr Semchenko, Academy of management of the Ministry of Internal Affairs of Russia, Moscow, Russia

Ekaterina Anatol'evnaSumina, Academy of management of the Ministry of Internal Affairs of Russia, Moscow, Russia

Sergey AlexandrovichKhmelev, Moscow University of the Ministry of Internal Affairs of Russia named by V.Ya. Kikot, Moscow, Russia

Ekaterina AlekseevnaTrishkina, Academy of management of the Ministry of Internal Affairs of Russia, Moscow, Russia

Svetlana Belova, Academy of management of the Ministry of Internal Affairs of Russia, Moscow, Russia

\section{PROPOSED METHODOLOGY}

Author The sociological survey results served as a basis for this research. 326 full-time law students (under the age of 24) and 87 professors took part in the survey. Questioning was carried out before the application of the described method and after, according to the results of training. The data of a sociological survey, "psychological indicators and motivational dominants" [2] formed the basis for identifying the stages of application of the method of problem-communicative education, as well as its improvement. Additional positive results have been noted, proving the need for its application in the training of lawyers.

\section{RESULTS ANALYSIS}

The national education system has a strict hierarchical structure. This puts excessive strain on students. Such a structure is believed to be the legacy of the Soviet pedagogical science with an over-emphasis on the rationalism in education. However, it turns out that in spite of all the advantages of rationalism, it is not the only way to increase the effectiveness of graduates' future work. It's obvious that students should have a clear understanding of how to apply their knowledge to particular situations in their professional activities. This is the main goal and axiom of the problem-communicative approach.

In fact, cognition is of a communicative character which makes it possible to ensure communication between different sciences and promote their compatibility. Consequently, the new approach came into being. Namely, it was the behavioral approach which uses the achievements in psychology, sociology, cultural anthropology and helps understand the essence of future activities in larger social systems.

These days, we can witness the shift from the systematic approach to a network one. The network that is opposed to a hierarchy is heterogeneous, asymmetrical, complex, and dynamic which represents live phenomena and processes.

Such contemplation help define the aims for the training of lawyers in the 21 st century such as building a global view of the world through acquiring comprehensive and diverse knowledge, developing of analytical skills and critical thinking; building the skills for effective and prompt problem resolution in the professional activities through developing creative thinking, initiative, responsibility, and the ability to resist undesirable impulses. 
The aforementioned aims can be achieved with the help of the problem-communicative approach to education. Moreover, it will help eliminate the following modern problems: the integration of science and education to improve the scientific support of the Russian education system, to ensure the university science potential, to promote training programs for the innovative activity, and to create a professional elite.

The question is whether the university can help students acquire not only theoretical knowledge but also practical skills that make them members of the professional community. If it is possible, then the university can be regarded to as "modern". The aim of the problem-communicative approach to education aims at developing students' proactive life position through overcoming expectations that something will change on its own. These expectations enhance negative stereotypes, sense of unpredictability, feeling of lack of control over social and economic processes, and this leads to inconsistency between input and outcome which inhibits the sense of responsibility and self-reliance. The problem-communicative approach prepares students to be able to apply the acquired knowledge to real situations in their future professional activities. Modeling of real-life situations, material and procedural problems with the account of multidisciplinary connections help create the atmosphere of trust and cooperation in the learning process. When students try to prove themselves, they engage in communication and constantly develop their skills (thinking, talking, and writing as professionals, voicing and defending their opinion, manage the conflict situations). Students have clear expectations of the learning results, develop the sense of responsibility and the ability to learn, get the opportunity to check the objectivity of knowledge, and are eager to improve and consolidate their knowledge.

In fact, due to the peculiarities of the development process, many crucial steps in the professional development of a lawyer can be viewed as a response to obstacles hampering the normal activity at the "aim - obstacle" level. The discovery takes place through overcoming a specific cognition barrier. The success in overcoming the obstacles increases the person's level of aspirations and creates "temporary perspectives" that stimulate activity and mental development. According to L. M. Fridman, it is important to create such a situation for students when they "face a hurdle or obstacle to achieving the goal, so there is a necessity to overcome the obstacle to achieve the desired goal" [3]. This approach is necessary since many students choose the higher education institution not according to their inner motives but according to taught values, attitudes, or imposition. This imposed motivation inevitably causes the disruption of activity, impedes professional adaptation and, consequently, leads to social chaos.

The aim of the problem-communicative approach is to create such situations that will offer students a problem that they do not know how to resolve [4], there is no existing algorithm [5] and that makes the students want to meet the need by resolving the problem. Barriers that inhibit the fulfillment of the needs motivate the activity, condition its content, and the change of phases [6].

The first phase is connected with guidance. The professor acts as an information carrier who supplies necessary initial data, motivates to solve the problems by creating the value deficit. Then, the students gather information and carry out the initial analysis of the situation in terms of the desired values necessary to meet the needs, the students also analyze the essence of the problem and estimate the probability to overcome the obstacles. Thus, the students develop the abilities to manage the unknowns and to define the goals according to internal and external factors.

Further, students stipulate the goal and the plan of actions; hope grows into confidence; then, there is motivation to implement the developed program. In other words, the second phase teaches how to plan. At this stage, a professor acts as an observer since the students work in pairs or in groups under information deficit. The professor consults them when necessary (when students need advice, when they lack information resources, or when the activity has stalled).

The third phase is concerned with the realization of the intended tasks. It is important to remember that "performing actions have great motivational potential that sometimes is even greater than the initial motivation. $\langle\ldots\rangle$ failures, significant work pressure, and input can cause aversion and make the person give up. On the other hand, success in the activity can help develop passion for work and create substantial additional motivation" [7]. The aim of this phase is to develop skills and excellence.

The final phase implies error correction and learning results tracking. The professor should involve students in error correction by encouraging students' self-reliance, motivation, and self-confidence.

\section{CONCLUSION}

The knowledge that students have acquired soon comes to be seen as a past achievement, which makes them define new goals and encourages to overcome new successive obstacles that differ in content.

Feedback is an important element of the problem-communicative approach. The professor should know how students relate to the learning process and their specialization; what they like or unlike about their education; what their expectations are. Students' opinion should not be neglected. The lack of mutual understanding and latent conflicts are likely to hinder the effectiveness of the learning process and, thus, undermine the basics of the problem-communicative approach.

\section{REFERENCES}

1. V. S. Stepin. "Theoretical knowledge: Structure, historical evolution", Moscow, 2000.

2. V.V. Pushkarev, E.I. Cherdymova, A.I. Prokopyev, M.G Kochurov, N.V. Shamanin, S.G. Ezhov, S.V. Kamenskaya,N.V. Kamenskaya,"Motivation and needs in the area of the spouses with different experiences of cohabitation",Dilemascontemporáneos: Educación, Política y Valores, vol. 6(41), 2019, p. 20.

3. L. M. Fridman,"Didactic basis for the implementation of tasks in education”, Moscow, 1971.

4. N. A. Menchinskaya,"Education goals",Ped. Encyclopedia, Vol. 2, Moscow, 1990.

5. G. A. Ball, "Theory of educational goals" Moscow, 1990.

6. R. Kh. Shakurov, "New psychological theory of activity: systematic and dynamic approach", Prof. education, vol. 1, 1995.

7. R. Kh. Shakurov, "Barrier as a category and its role in performance",Issues of Psychology, vol. 1, 2001, pp. 3-18. 